hoy día presenta un gran cúmulo de huesos. El conjunto formado por la Torre, la puerta de poniente, con su matacán superior, y el aljibe ubicado a sus pies, precisa una buena rehabilitación, por su evidente importancia monumental y por tratarse del testimonio último en pie de las defensas de Motril en la Edad Moderna.

José Policarpo Cruz Cabrera Universidad de Granada

\title{
LA PÍXIDE DE MARFIL VI DE SAN PEDRO DE LA RÚA DE ESTELLA (NAVARRA), LOCALIZADA EN EL METROPOLITAN MUSEUM DE NUEVA YORK
}

El objeto de este estudio ${ }^{1}$ es una píxide de marfil de forma cilíndrica $(9 \times 11,5 \mathrm{~cm}$.) que procede de la parroquia de San Pedro de la Rúa de Estella (Navarra) y se encuentra en la actualidad en el Metropolitan Museum de Nueva York. En el cilindro exterior se representa la escena de la Multiplicación de los panes y los peces. La tapa se decora con motivos geométricos.

La primera mención que encontramos en la bibliografía acerca de esta pieza la hace Madrazo en 1886. Antes no hemos hallado ninguna noticia de importancia en los archivos parroquiales, ni en los inventarios hechos en $1849,1850-1859,1860$ y $1880^{2}$. Madrazo no da muchos datos pues sólo examinó el relicario donde se guardaba durante un tiempo brevísimo, y no pudo valorarla adecuadamente: la arqueta de marfil que fijó nuestra atención ... es un objeto de arte primoroso, cubierto en su contorno de bajo-relieves del estilo del renacimiento, en cuya interpretación no pudimos detenernos ${ }^{3}$. Después, la píxide ha sido estudiada cuando ya se encontraba en la colección de John P. Morgan, en primer lugar por E. Baldwin Smith, que la fecha en el siglo VI, establece su origen alejandrino-copto y estudia su iconografía en relación con otras representaciones eucarísticas ${ }^{4}$. Más tarde, Joseph Breck realizó un estudio sobre los marfiles anteriores a la época gótica existentes en la colección

1 Queremos expresar nuestro agradecimiento al Departamento de Historia Medieval del Metropolitan Museum de Nueva York, a la Bodleian Library de Oxford, a Jesús Iricíbar por la confección de los dibujos y a la Pfra. Fernández-Ladreda por sus indicaciones.

2 Archivo Parroquial de San Pedro de la Rúa. Estella (Navarra). Libro 071. Inventarios de la Parroquia de San Pedro. Sólo se nombra en el inventario de 1849, en la p. 14, con el núm. 149 «... un cetro [báculo], unos guantes y vinajeras que trajo el Sr. obispo de Patrás y una caja que parece de brasil [¿marfil?] en la [que] traía la Santa reliquia de San Andrés, y con el núm. 160, ... diferentes reliquias que se hallan en el altar de la capilla del dicho Santo». Otro inventario, sin fecha, en la p. 20. (entre 1850 y 1859) habla de ... las alhajas y reliquias que se conservan en los armarios del retablo de San Andrés ... Es decir, la píxide se guardaba en un relicario que formaba parte del retablo rococó que se encuentra en la capilla de San Andrés de esa parroquia, junto con otros muchos relicarios y otros objetos, entre ellos, los dejados allí por el obispo de Patrás.

3 Pedro de Madrazo, España. Sus monumentos y artes. Su naturaleza e historia. Navarra y Logroño, vol. III, Barcelona, 1886, pp. 81-83. En la p. 50 dice que consultó un manuscrito titulado Extracto de la historia de Estella escrita en el año 1644 por D. Francisco de Eguía y Beautman, hijo de ella, y allí leyó que en el altar de San Andrés de la parroquia de San Pedro de la Rúa (que no es el actual, de estilo rococó y de la segunda mitad del siglo XVIII) había un relicario muy rico, que contenía: parte del omóplato del apóstol San Andrés, ... otra reliquia de San Fermín y cuatro cajas de marfil llenas de reliquias de santos cuyos nombres se ignoran.

4 E. Baldwin Smith, Early Christian Iconography and a School of ivory carvers in Provence, Princeton, 1918, pp. 129-141. 
Morgan, incluyendo la píxide de San Pedro de la Rúa aunque sin citar su procedencia, clasificándola como egipcia o siria, con más probabilidades a favor de Egipto y la data también en el siglo VI ${ }^{5}$. Edward Capps publicó en 1927 un estudio sobre una píxide del Museo Cristiano en la Biblioteca Vaticana y puso su estilo en relación con la que tratamos ahora, siguiendo la opinión de E. Baldwin Smith en cuanto a la procedencia egipcia ${ }^{6}$. En 1949 Helmut Schlunk escribía en la sección de Varia de Archivo Español de Arqueología una reseña de la exposición sobre arte bizantino y paleocristiano celebrada en la Galería Walters de Baltimore dos años antes, con motivo del bicentenario de la fundación de la Universidad de Princeton. Con respecto a los objetos de procedencia española, menciona la píxide de San Pedro de la Rúa, cita a Madrazo, la clasificación hecha por Edward Capps y publica una fotografía, dándola así a conocer en nuestro país, aunque sin ningún eco. Reconoce la procedencia islámica de la tapa y anuncia un artículo que habría de publicarse en la Revista Príncipe de Viana, que, desgraciadamente, no llevó a cabo ${ }^{7}$. Wolfgang Fritz Volbach la incluyó en su corpus de marfiles antiguos y medievales publicado en 1976, y puede decirse que se trata del estudio más completo entre todas las fuentes consultadas. Incluye un total de cuarenta y seis píxides entre los siglos V y IX, estableciendo estilos, escuelas, talleres, relaciones estéticas e iconográficas, utilizando toda la bibliografía aparecida hasta entonces, y dando la clasificación que consideramos definitiva ${ }^{8}$.

Con todo, la píxide de San Pedro de la Rúa, a pesar de su importancia y desde luego, su singularidad en el panorama de la eboraria española, no ha sido tratada ni en los estudios especializados sobre la antigüedad tardía occidental o bizantina ni en los dedicados al estudio de la talla del marfil, al menos como antecedente de la feraz producción posterior, musulmana o cristiana ${ }^{9}$. Tuvimos la suerte de descubrir noticias inéditas sobre esta pieza mientras se realizaba la investigación sobre las actividades de la Comisión de Monumentos de Navarra. Entre sus documentos encontramos la fotografía de Laurent (figs. 15 y 16) y la correspondencia mantenida entre distintos miembros de la Comisión intentando averiguar el destino de la píxide, que ya no estaba en 1911 en la parroquia de San Pedro de la Rúa ${ }^{10}$. Más tarde la pudimos localizar en su emplazamiento actual, y rehacer su historia con todos los datos reunidos que tenemos la posibilidad de ofrecer ahora.

5 Joseph Breck, «Pre-Gothic ivories in the Pierpoint Morgan Collection», en Bulletin of the Metropolitan Museum of Art, New York, 1920, p. 14.

6 Edward Capps, Jr., «An ivory pyxis in the Museo Cristiano and a plaque from the Sancta Sanctorum», en The Art Bulletin, IX, 1927, pp. 331-341.

7 Helmut Schlunk, «The Walters Gallery. Early Christian and Byzantine Art. An exhibition at the Baltimore Museum of Art. April 25 - June 22, 1947, Baltimore, Walters Art Gallery, 1947» en Archivo Español de Arqueología, 1949, pp. 207-213.

8 Wolfgang Fritz Volbach, Elfenbeinarbeiten Der Spätantike und des Früen Mittelalters, Mainz am Rhein, 1976. Se refiere a las píxides en las pp. 103-121, y figs. 161-201. En concreto, a la de Estella, en la p. 106 y figs. 165 y 166.

9 Danielle Gaborit-Chopin, Ivories du Moyen Age, Fribourg, 1978, no trata acerca de la píxide objeto de este estudio, pero conoce su existencia, pues en un mapa en la p. 18 indica Estella como lugar de procedencia de una pieza de marfil antigua.

10 Emilio Quintanilla Martínez, La Comisión de Monumentos históricos y artísticos de Navarra, Pamplona, 1995, pp. 287-288. Aquí publicamos la venta de la píxide dentro del marco de las ventas irregulares de bienes eclesiásticos que tuvo lugar en la diócesis de Pamplona a principios del siglo XX. También se publicó la fotografía entonces disponible, la de Laurent, que muestra sólo la parte central en la que se ve a Cristo entronizado entre dos apóstoles realizando el ademán de entregarles algo, por lo que supusimos, erróneamente, que se trataba de la escena de la Traditio Legis. 


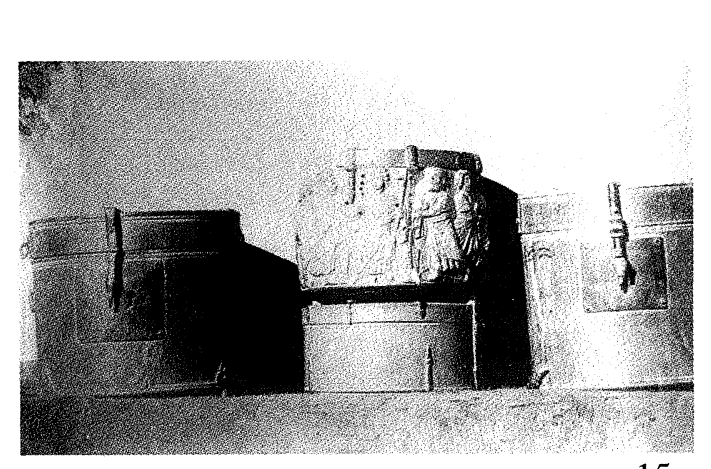

15

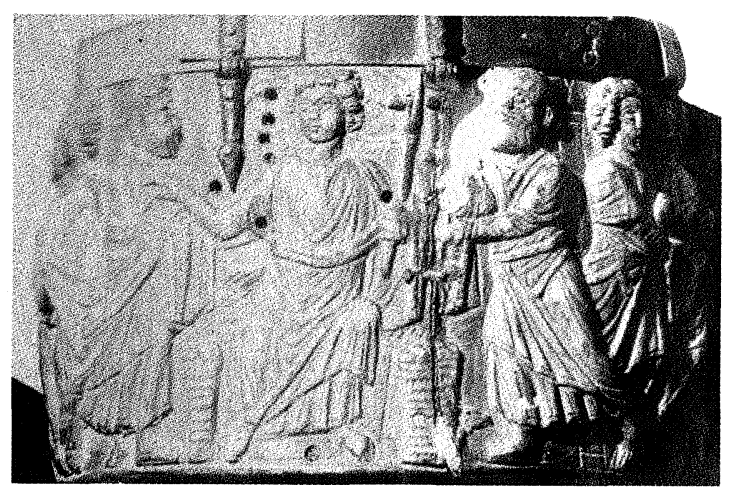

16

Figura 15. Píxide de San Pedro de la Rúa. Estella (Navarra). Figura 16. Píxide de San Pedro de la Rúa. Estella (Navarra). Hacia 1911.

Hacia 1911.

El origen de las píxides se remonta a la época de la Grecia arcaica, y eran en principio pequeñas cajas cerámicas, normalmente de sección circular, vasos con tapa, que se utilizaban para guardar cosméticos. La cultura cristiana adoptó estas formas para contener objetos relacionados con el culto divino, realizándose en marfil por ser su forma cilíndrica muy adecuada para aprovechar una sección del colmillo del elefante. Se utilizaron como recipiente de incienso y, sobre todo, como hostiarios. Más tarde se usaron también para contener reliquias ${ }^{11}$, como ocurrió con la que nos ocupa, cuya finalidad eucarística parece clara por el tema que se desarrolla en su superficie, y que luego fue reutilizada en Estella como relicario.

La píxide de San Pedro de la Rúa está decorada con una representación del pasaje neotestamentario de la Multiplicación de los panes y los peces. Esta escena fue relatada por los cuatro Evangelistas, aunque se suele seguir la narración de San Juan por ser la más completa de todas ellas y la que incorpora más elementos descriptivos ${ }^{12}$. Centra la composición la figura de Cristo entre dos apóstoles (fig. 19), al que se,representa joven, imberbe, sin nimbo, sentado

11 W. F. Volbach, Elfenbeinarbeiten ..., p. 103. Dice que el Concilio de Narbona (589) prescribía su uso para reservar la Eucaristía, y que se solían colgar sobre el altar. Este autor expone de nuevo el mismo uso en Avori di scuola ravennate nel V e Vi secolo, Ravenna, 1977, p. 32. De la misma opinión son J. Breck: Op. cit, p. 14 y Georg Lehnert, Historia de las Artes Industriales, vol. I, Barcelona, 1930, pp. 134-135.

${ }_{12}$ Mt. 14, 15-21; Mt. 15, 32-38; Mc. 6, 35-44; Mc. 8, 1-9 (cita dos multiplicaciones); Lc. 9, 12-17 y la más amplia: Io., 6, 5-13: ... Jesús alzó los ojos, y viendo venir a mucha gente, dijo a Felipe: "¿Dónde compraremos panes para que coman todos ellos?» Decía ésto para probarlo, pues Él sabía lo que iba a hacer. Felipe le contestó: "Doscientos denarios de pan no bastan para que cada uno de ellos tome un poco». Dijo entonces uno de los discípulos, Andrés, el hermano de Simón Pedro: «Aquí hay un muchacho que tiene cinco 
en un trono, vestido con túnica y pallium y calzado con caligae. Extiende el brazo derecho y toca el pan que le presenta un apóstol. Con la mano izquierda empuña un centro enhiesto rematado por una cruz de brazos iguales y otra incisa en su interior, y sujeta la punta del $p a-$ llium que cae diagonalmente sobre su regazo. El trono es de respaldo recto, tiene un amplio almohadón en el asiento y dos elementos anchos verticales que pueden ser las patas del trono o quizás, por su forma, dos cestos. Ambos apóstoles aparecen vestidos de la misma manera, como el resto de las figuras, y se distinguen pos su barba, terminada en pico en el de la izquierda y cuadrada el de la derecha, cabellos lisos, cortos, aplastados y peinados en líneas paralelas. Diez personajes más completan la escena (figs. 17, 18, 20 y 21), jóvenes, sin barba y con el cabello corto en grandes bucles que cubren las orejas, similares a los de la figura de Cristo. Todos llevan, sujetos sobre el borde de sus mantos, que envuelven sus brazos ocultando las manos, los panes que les han entregado los apóstoles, ya bendecidos, para distribuirlos. Uno de ellos (fig. 3) se agacha para aprovechar el sitio más reducido del que dispone, pues está limitado por el espacio necesario para poner la cerradura de la caja. La ubicación de la escena se realiza de manera simbólica (el relato evangélico cuenta que la Multiplicación tuvo lugar al aire libre) por medio de arcos de medio punto algo rebajados sobre columnas, dibujados de manera muy lineal y somera, correspondiendo un arco a cada personaje. La distribución arquitectónica, sin embargo, no constriñe el movimiento de las figuras, sino que éstas rompen los límites que les impone su marco y, a veces, en la simulación del acto de caminar, invaden el espacio del personaje siguiente, lo cual da a la escena un sentido dinámico muy apreciable, incluso el de una cierta agitación bastante realista, sugerida por la ruptura del ritmo vertical de los cuerpos, la aparición de diagonales por el movimiento y por el hecho de no caminar todas las figuras en la misma dirección, sino que se cruzan entre ellos, avanzando en sentido contrario o volviendo la cabeza hacia el que tienen detrás. Eso hace que no encontremos la simetría ni el ritmo procesional que podía esperarse, ni tampoco una repetición de un solo modelo, sino una cierta tendencia a la individualización de las figuras, en las que, pese al parecido de los rasgos, de facciones grandes y óvalo ancho, hay un cierto deseo de diferenciación, que se hace más evidente en sus gestos no repetitivos, en las distintas formas de doblar el manto sobre el brazo para sostener los panes, en el movimiento de la parte inferior de las ropas y en la variedad de posturas que adoptan los personajes, aparentemente idénticos.

Si comparamos la fotografía (fig. 16) realizada en los primeros años del siglo XX que se conserva en el Archivo de Príncipe de Viana con las que muestran el estado de la píxide en la actualidad (fig. 19), podemos apreciar muy pocos cambios, aunque algunos de ellos son perceptibles. Por un lado, el reborde que ajusta la tapa con el cuerpo de la píxide, que a principios de siglo parece estar completo, se ha perdido en un cuarto del total, y aparece roto en otros lugares. Esta zona está decorada con los mismos motivos geométricos que la tapa, de lo que se puede deducir que fue realizada al mismo tiempo que ésta.

panes de cebada y dos peces. Pero ¿qué es esto para tantos?» Dijo Jesús: «Hacedlos sentar». Había mucha hierba en aquel sitio. Se sentaron, pues, alrededor de cinco mil hombres. Tomó Jesús los panes, dio gracias y distribuyó entre los que estaban sentados, cuantos panes quisieron, y lo mismo hizo con los peces. Cuando se saciaron, dijo a sus discípulos: «Recoged los trozos sobrantes para que no se pierda nada». Los recogieron y llenaron, de los cinco panes de cebada, doce cestos de trozos que sobraron a los que habían comido. Muchas veces es imposible saber a cuál de los relatos evangélicos se refiere la escena, sólo es posible distinguirlos a veces por el número de los cestos, cinco si se habla de la primera multiplicación o siete si lo es de la segunda (Mt. y Mc.). 


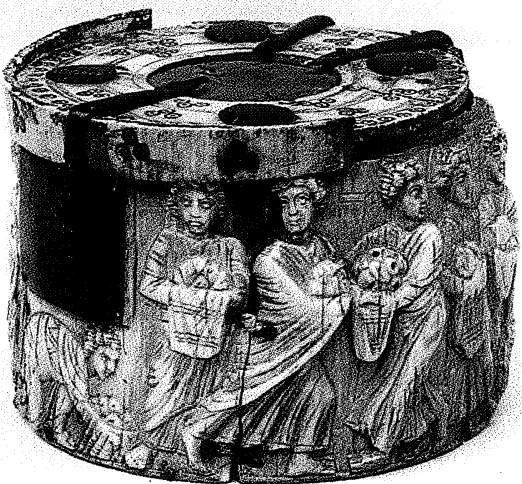

17

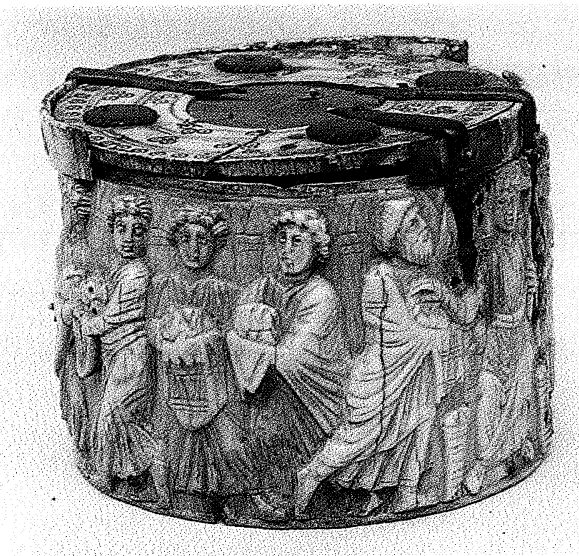

19
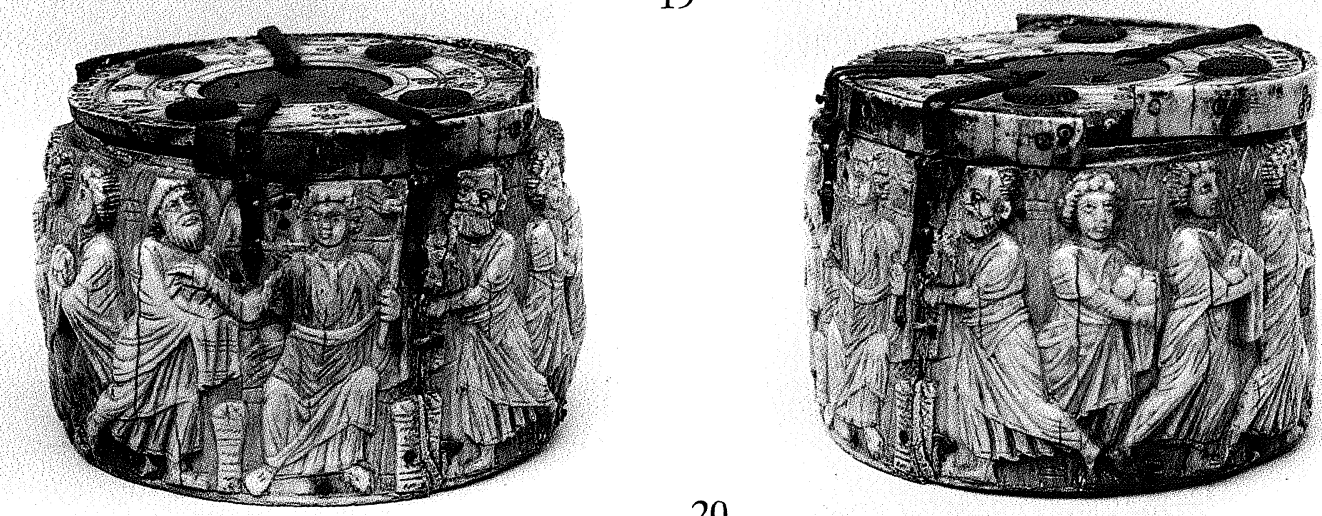

21
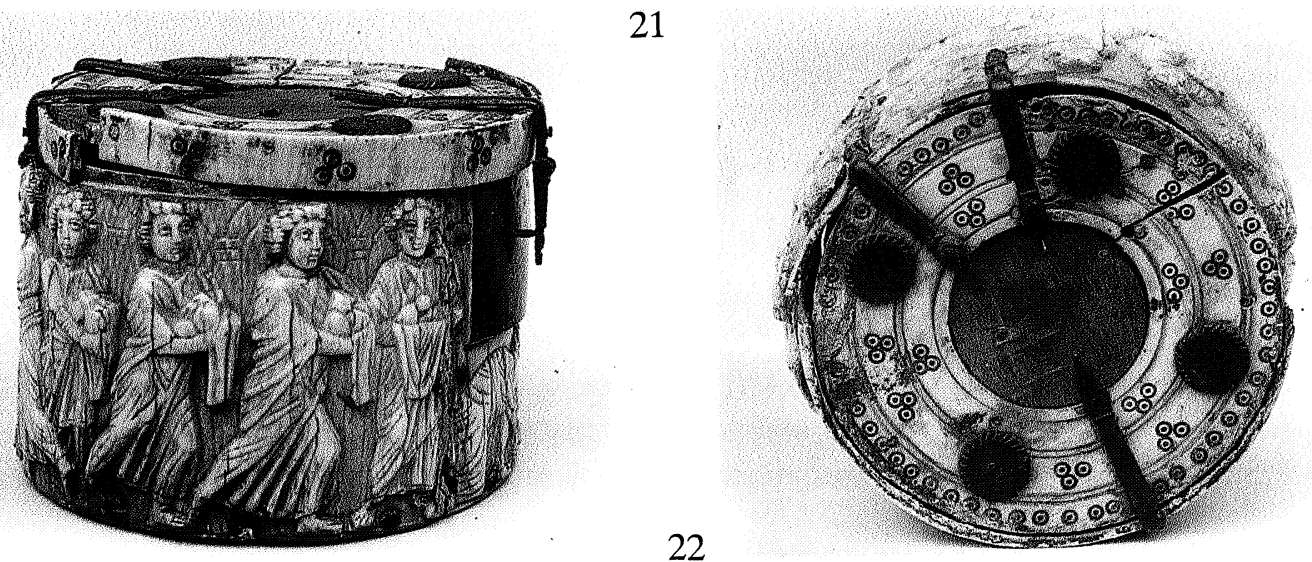

Figuras 17-22. Píxide de San Pedro de la Rúa, de Estella (Navarra). Detalles, Nueva York. Metropolitan Museưm. (All rights reserved.) 
Analizando los goznes, se ve que hoy tiene uno, el de la derecha, que no se aprecia en la foto antigua, y habrá sido hecho a semejanza del conservado. Hay también algunas grietas que antes no se veían (sobre el vientre de la figura central, en el brazo del apóstol de la derecha, en el pie del de la izquierda) y una fisura, perceptible a principios de siglo, sobre la parte derecha del trono, que recorre la totalidad de la pared de la pieza de arriba a abajo, rellena hoy con una materia que imita la textura del marfil. Esta hendidura, bien visible, parece indicar que la píxide se partió en tres trozos, por la parte que indicamos y a ambos lados de la pieza metálica de la cerradura, y se volvieron a pegar, sujetándolas por medio de grapas o lañas, hoy desaparecidas, cuyas marcas se conservan. Hay también marcas en la parte inferior que pueden deberse a las huellas de grapas usadas para sujetar la base al cuerpo de la píxide.

En las distintas marcas circulares que se aprecian a los lados de la cabeza de Cristo, algunas de las cuales han sido rellenadas de pasta, podemos rastrear la historia de los distintos goznes que ha tenido la pieza. Los originales serían muy pequeños y no invadirían el campo del relieve; pues, de haber sido así, el autor hubiese dejado algún espacio sin labrar para ello y hubiese cambiado la disposición de las figuras, como hizo en el lado de la cerradura, donde uno de los personajes se agacha para dejar libre ese espacio (fig. 25). Luego, es posible que se pusiesen otros goznes, en este caso invadiendo el relieve, que, ateniéndonos a las marcas dejadas, irían a los lados de la cabeza de Cristo, enmarcando el torso. Por último, las actuales, de factura islámica, una de ellas imitada en época contemporánea, que dejan más espacio a los lados de la figura, pero rompen el cetro, en concreto, uno de los lados de la cruz del remate, e imposibilitan la visión de lo que presenta para ser bendecido el apóstol de la derecha.

Sin querer entrar en la discusión de términos, de si estamos ante una obra paleocristiana o protobizantina, sí que diremos que, atendiendo al estilo, nos parece más próxima al espíritu romano —o al helenístico- que al bizantino, si consideramos la tendencia al alejamiento de los modelos naturales como un rasgo propio de ese estilo. Si bien ya encontramos evidentes rasgos no naturalistas, como la falta de perspectiva o el acortamiento del canon, otros factores nos acercan al naturalismo, y entre ellos destacaríamos la plasmación del movimiento, de una actividad dinámica, incluso algo ajetreada, la sensación de volumen y el naturalismo en la labra de los pliegues de las ropas y de los cuerpos, que se adivinan bajo las vestiduras. Esta pervivencia quizás se explique por su origen egipcio y, en concreto, alejandrino.

Hay una cierta unanimidad en los distintos autores consultados acerca del origen de la píxide y su datación: Egipto y el siglo VI. Así la cataloga el primero en hacerlo, E. Baldwin Smith ${ }^{13}$, considerándola como una prolongación del mismo tema representado en la cátedra de Maximiano de Rávena. Joseph Breck sigue su opinión, aunque uniendo la posibilidad de una procedencia siria ${ }^{14}$. Edward Capps, en su estudios sobre unas obras en marfil de la Biblioteca Vaticana establece las siguientes características que revelan un origen egipcio, copto, según sus palabras: la presencia de la figura de Cristo con el pelo corto, imberbe, llevando el cetro crucífero; el pelo como una peluca, rizado o cortado recto como para formar un flequillo; el tratamiento de los ojos, con el iris rehundido y el párpado inferior ligeramente resaltado, el tratamiento esquemático de los ropajes que muestra una marcada

13 E. B. Smith, Op. cit, p. 133.

14 J. Breck, $O p$. cit, p. 14, aunque en la p. 13 afirma que atribuir una procedencia siria o egipcia es a menudo un affair of divination. 
dependencia de la línea incisa; el uso del sombreado por medio de una retícula de líneas formando una trama regular, utilizado sobre todo en los almohadones, y el fondo de arquitectura que considera una reminiscencia del ilusionismo alejandrino, cualidades todas ellas que se observan en la píxide y en la placa vaticanas que analiza y en la de San Pedro de la Rúa. A estas características añadiríamos el sentido del movimiento que apuntábamos antes, tan evidente en esta obra, que sería una reminiscencia helenística. Además, Capps afina aún más la cronología, fechando la de Estella entre los años 506 y $525^{15}$. Volbach estudia un total de cuarenta y seis píxides con motivos cristianos, e incluye dos con el tema de la Multiplicación: la de Estella y otra muy similar, aunque más deteriorada, conservada en el Museo Civico de Livorno. El fondo arquitectónico es el mismo, así como Cristo entronizado tocando los alimentos que le ofrecen las figuras de los lados, que son jóvenes y no barbados igual que en la de Estella, como los que se los llevan para distribuirlos. Algunas posturas son idénticas en ambas obras, como las de los personajes que se portan los panes y vuelven la cabeza, es el mismo el ambiente de un cierto ajetreo y el juego de diagonales. Los deterioros de la parte derecha no permiten apreciar la escena que se representa en ese lado. Sí vemos que hay un águila debajo del espacio de la cerradura, en el lugar que en la píxide de Estella ocupa el joven agachado. La píxide de Livorno procede de Cartago y se fecha también en el siglo VI, aunque Volbach no propone ningún lugar en donde fuese realizada. Además, introduce un nuevo dato, al afirmar que la píxide del Museo Dell'Alto Medioevo de Roma está emparentada estilísticamente con la de Estella, y que pudo haberse hecho en o cerca de Rávena ${ }^{16}$. Ese mismo autor insiste en otra publicación posterior ${ }^{17}$ en la posible procedencia de Rávena, dada la movilidad de los artistas, que ejemplifica con la cátedra de Maximiano, en la que se ven influencias de Alejandría, Bizancio y Siria en las distintas placas de esa obra, para acabar afirmando, dado el cruce de influencias y de artistas, y la enorme facilidad en el transporte de este tipo de objetos, que ... podemos hacer una comparación entre los relieves mencionados más arriba, y el grupo de píxides que se discute, pero en la mayor parte de los casos no es posible pronunciarse sobre su proveniencia, la cual resulta problemática ${ }^{18}$. La posible procedencia italiana de la píxide de San Pedro de la Rúa haría más fácil explicar su presencia en España, simplemente por la mayor proximidad geográfica y también de ámbito cultural que si proviniese del Mediterráneo oriental, de Siria o Egipto. Con todo, esto último no sería imposible, desde luego, dado el pequeño tamaño de este tipo de objetos. Sin embargo, sólo tenemos noticias de dos objetos orientales del siglo VI conservados en España hasta fechas recientes: éste y el díptico de Oviedo, tallado en Constantinopla pero traído desde Roma.

Parece bastante lógico que se talle la escena de la Multiplicación de los panes y los peces en el exterior de una píxide, dado que su finalidad era la reserva eucarística (fig. 23). Sin em-

15 E. Capps, Jr., Op. cit, pp. 331-340. Margaret Gibson, Late antique and medieval ivory and bone carving in Liverpool Museum and the Walker Art Gallery, London, 1944, nos sugiere el fin del siglo VI como fecha ante quam; según esta autora, la talla del marfil clásico terminó en el siglo VII, por diversas razones que explicarían la ịmposibilidad de conseguir la materia prima, entre ellas la conquista musulmana del norte de África, que cortaría las vías de abastecimiento tradicionales: la talla del marfil cesó de practicarse de manera repentina e universal (p. 23). Apunta que el renacimiento de este arte renació en la corte de Carlomagno.

16 W. F. Volbach, Elfenbeinarbeiten ..., pp. 103-121 y figs. 161 a 201.

17 W. F. Volbach, Avori di scuola ravennate...

18 Idem, p. 32. Rávena, como nuevo centro de poder imperial, se convierte en un centro de atracción para muchos artistas y resulta, por lo tanto, muy difícil individualizar las diversas escuelas. 
bargo, en el corpus de Volbach ${ }^{19}$ sólo se incluye otra con ese mismo tema. Son motivos más corrientes el Sacrificio de Abraham (que también suele simbolizar el de Cristo y, por lo tanto, la Eucaristía), Daniel en el foso de los leones, Jonás, la resurrección de Lázaro, es decir, prefiguraciones de la Resurrección de Cristo, o temas en los que se manifiesta su poder salvífico, como en la Curación del paralítico o la Hemorroísa, o temas de su Infancia como la Epifanía, es decir, asuntos muy similares a los tratados en los sarcófagos paleocristianos. La escasa presencia de temas específicamente eucarísticos puede indicar que el uso de este tipo de objetos no sólo era el de contener las Formas, sino otros, también apuntados por varios autores, como el de receptáculos de incienso o reliquias.

La Multiplicación de los panes y de los peces es uno de los principales símbolos de la Eucaristía ${ }^{20}$, y fue utilizado con profusión en el arte paleocristiano. La representación más antigua de este tema se da en las catacumbas de Priscila, del siglo II ${ }^{21}$, donde se incluyen unas cestas con panes dentro de la escena de un ágape eucarístico. La escena concreta de la Multiplicación se comienza a representar en el siglo III, y aparece Cristo tocando los cestos de panes con una vara ${ }^{22}$. Ya en el siglo IV se convierte en uno de los temas más comúnmente representados en los relieves de los sarcófagos ${ }^{23}$. En ellos vemos a Cristo, en pie, tocando con la vara taumatúrgica los cestos de los panes o con las manos los panes y peces que le presentan los apóstoles, a veces sólo uno o un número impar, a un lado, y resulta una escena asimétrica, o dos, uno a cada lado, estableciéndose la simetría. De esta misma forma es como se plasma la escena en los sepulcros paleocristianos romanos estudiados por G. Wilpert y casi exactamente igual en lo españoles tratados por M. Sotomayor, en los que la iconografía romana se repite en diez ocasiones en otros tantos sarcófagos del siglo IV: Cristo joven, sin barba, impone las manos, en el gesto de bendición sobre los panes o peces que les presentan los apóstoles a uno o a ambos lados, sin utilizar la vara, que se reserva para otro tema eucarístico paralelo: la escena de la Conversión de agua en vino de las Bodas de Caná ${ }^{24}$. Podríamos así establecer un modelo iconográfico occidental en la cuarta centuria durante la cual aparece Cristo en pie, modo que persiste todavía en el siglo VI en la cátedra de Maximiano. En Oriente tendríamos una manera diferente de representar la misma escena, con Cristo sedente en un trono. Así aparece en un fresco de las Catacumbas de Alejandría, del siglo III donde vemos a Cristo en el centro, con nimbo crucífero, entronizado, tocando con las manos los alimentos que le presentan por cada lado los apóstoles Pedro y Andrés (identificados por inscripciones) ${ }^{25}$. Si aceptamos la proveniencia egipcia de la píxide de San Pedro de la Rúa, o esa influencia, si hubiese sido producida en Rávena, aquí estaría su fuente iconográfica y no en la cátedra de Maximiano, donde Cristo aparece en pie. El tipo físico con el

19 W. F. Volbach, Elfenbeinarbeiten ...

${ }^{20}$ En esto coinciden los autores consultados: E. B. Smith. Op. cit; pp. 130 y ss.; Giuseppe Wilpert, I sarcofagi cristiani antichi, vol. II, Roma, 1932, pp. 307-309; G. Duchet-Suchaux; M. Pastoreau, Guía iconográfica de la Biblia y los Santos, Madrid, 1996, pp. 282-283; James Hall, Diccionario de temas y símbolos artísticos, Madrid, 1996, p. 269; Louis Réau, Iconografia del arte cristiano, tomo I, vol. 2, Barcelona, 1996, pp. 381-385.

${ }^{21}$ E. B. Smith. Op. cit; p. 130; G. Wilpert, Op. cit, p. 307; L. Réau, Op. cit, p. 384.

22 Como en el fresco de un cubiculum del cementerio de Domitila, citado por L. Réau, Op. cit, p. 384.

23 L. Réau, Op. cit, p. 384; E. B. Smith, Op. cit, p. 131.

24 M. Sotomayor, Sarcófagos romano-cristianos de España, Granada, 1975. En los sarcófagos romanos estudiados por Wilpert a veces se ve a Cristo tocando con la vara taumatúrgica los cestos de los panes, pero eso ocurre cuando en el mismo sarcófago se representa simétricamente la Conversión del agua en vino, contagio de formas que se debe sin duda a razones de proximidad.

${ }_{25}$ E. B. Smith, Op. cit, p. 133, fig. 124. 


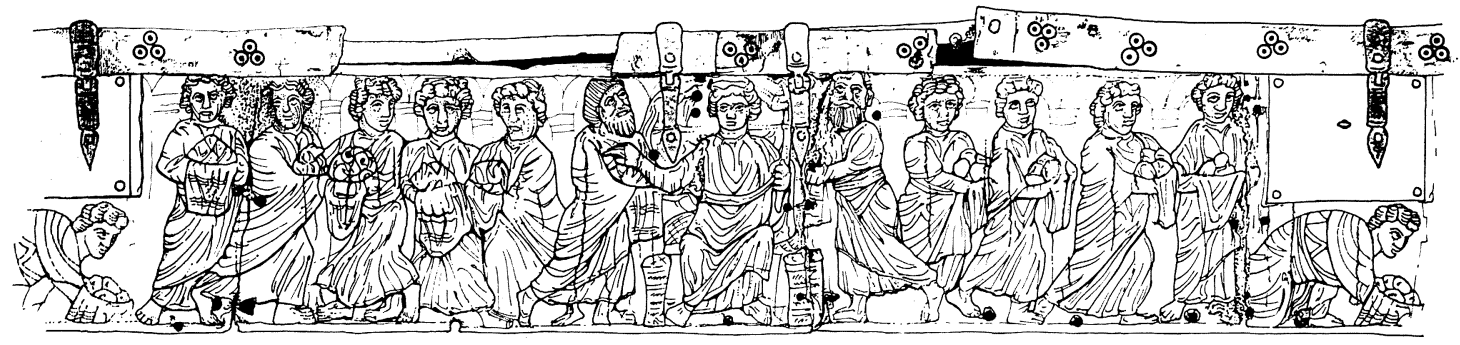

23

Figura 23. Púxide de San Pedro de la Rúa, de Estella (Navarra). Desarrollo de la escena de La multiplicación de los peces.

que se representa al Salvador en la píxide estellesa responde a un hombre joven, el tipo que llama Sotomayor ${ }^{26}$ Cristo-héroe, y entronizado, Cristo-juez. La reflexión sobre el por qué se produce la variación iconográfica en Oriente con respecto al mismo tema en Occidente (Cristo erguido frente a Cristo entronizado) nos lleva a creer que se debe a dos razones principales. Una quizás sea una mayor solemnidad en la representación oriental, un mayor simbolismo frente al naturalismo romano. En el primer caso, Cristo realiza el milagro desde el trono, símbolo de autoridad, destacando su condición divina; en el segundo, está en pie y subraya de alguna manera su condición humana. Otra razón puede ser la influencia del tipo iconográfico que se denominará Cristo en majestad. El origen de la representación de la divinidad de Cristo está en las imágenes de la majestad del emperador ${ }^{27}$ y también en la de los dioses paganos y se comenzó a realizar a mediados del siglo IV, según A. Grabar, en los sarcófagos y en la pintura mural, añadiendo la sensibilidad de la nueva religiosidad ${ }^{28}$. El tema tendrá una gran perduración posterior. En el caso que nos ocupa, el trono está enmarcado por un arco y tiene un respaldo de remate recto, a la altura de los hombros de Cristo. Éste se sienta sobre un almohadón cuyo volumen se resalta por medio de la retícula incisa que es, según Capps, característico de la escuela alejandrina, como hemos visto, así como también lo sería el cetro que empuña, rematado por una cruz a la que ese mismo autor llama «copta», afirmando taxativamente que sólo se encuentra en monumentos de origen egipcio ${ }^{29}$. El cetro

26 M. Sotomayor, Op. cit, p. 51.

27 En el arco de Constantino vemos al emperador sentado en un trono repartiendo mercedes a figuras que se encuentran a los lados, escena que puede servir como antecedente remoto de la que estamos estudiando.

28 André Grabar, El primer arte cristiano (200-395), Barcelona, 1967. p. 44.

29 E. Capps, Op. cit, p. 332. 
reemplaza a la vara taumatúrgica utilizada con ocasión de otros hechos milagrosos, y da originalidad a la escena, pues sólo puede tocar lo que le presenta el apóstol a su derecha al llevar el cetro en la mano izquierda. A los pies del trono hay dos cestas, presentes invariablemente en esta escena. Se trata de cestos altos, ensanchados en la parte superior, con incisiones que nos indican el trenzado de la cestería, llenos con panes de no gran tamaño, de los llamados decussati por tener un aspa incisa, que se hacía para facilitar su fraccionamiento. Ese tipo de cesto es el corriente en todos los casos similares que hemos revisado.

A los lados de Cristo vemos a dos apóstoles, que se distinguen de los demás personajes por sus peinados y barbas. El de la izquierda con bastante cabellera y barba apuntada y el de la derecha con menos pelo y barba cuadrada. Estos personajes podrían haberse identificado en una primera lectura con San Pedro y San Pablo. Sin embargo, San Pablo no pudo estar presente en ese acontecimiento, y será, como confirman los letreros que los identifican en el fresco de las catacumbas de Alejandría al que hicimos antes referencia, San Pedro y San Andrés ${ }^{30}$. Otro factor curioso de la escena de nuestra píxide es el que los panes son bien reconocibles, pero no así los peces, que no se ven porque van envueltos en paños, formando unos paquetes, tanto el que le presenta el apóstol de la izquierda como los que se llevan los dos jóvenes inmediatos a él (fig. 21). Además, y esto también singulariza esta escena en concreto, todas las figuras sostienen los alimentos con las manos veladas. Esto no ocurre en ninguna de las escenas de la Multiplicación que hemos analizado entre las producidas en Occidente. Sí que se da en la otra píxide que Volbach considera relacionada iconográficamente con la de San Pedro de la Rúa, la del Museo Civico de Livorno ${ }^{31}$. De nuevo podríamos explicar esta peculiaridad recurriendo a otro tema por el que se vería influido: el de la presentación de las coronas, que se da, por ejemplo, en la cubiertas de libro de marfil de la catedral de Milán, o en los mosaicos de Rávena. En estos casos lo mártires presentan a Cristo — sentado- los símbolos de su santidad con las manos veladas con un paño o, más corrientemente, con el borde de su manto. Esta posibilidad abre otra incógnita acerca del origen de la píxide. Si aceptamos Alejandría, como parece lo más probable, según las características formales enunciadas por Capps, no se dio allí esta forma de sostener los objetos velados, como tampoco se da en el fresco de las catacumbas de Alejandría que suponemos el precedente inmediato de la iconografía de la píxide de Estella. El velar las manos parece algo más propio de las manifestaciones figurativas de Rávena. Por todo eso, no parece demasiado descabellado aceptar la sugerencia de Volbach de que, dada la movilidad de los tallistas de marfil y la atracción que supuso Rávena como centro del poder político y artístico en su época ${ }^{32}$, ese pudiera ser el lugar de origen del marfil de San Pedro de la Rúa, obra de un artista alejandrino, que conservó los tipos y formas de su lugar de origen y asimiló nuevas formas en Rávena.

${ }^{30}$ M. Sotomayor, Op. cit, p. 51, sostiene la teoría, cuando trata acerca de esta misma confusión, que se da en el sarcófago de Astorga, sobre la definición de los tipos iconográficos de los apóstoles. según la cual, sería tardía, y los apóstoles que presentan los alimentos a Cristo no buscan una identificación, sino que, simplemente, se diferencian sus rasgos para romper la simetría rigurosa. Sin embargo, E. B. Smith, Op. cit, p. 142 dice en el siglo V la iconografía de San Pedro y San Pablo estaba ya firmemente establecida. De todos modos, apuntamos la coincidencia de que sea un pasaje relacionado con la vida de San Andrés el que se representa en la píxide de Estella conservada hasta principios del siglo XX en una iglesia muy vinculada a ese apóstol.

31 W. F. Volbach, Elfenbeinarbeiten ..., p. 106, fig. 165.

32 W. F. Volbach, Avori di scuola ravennate ..., pp. 11 y 32. 


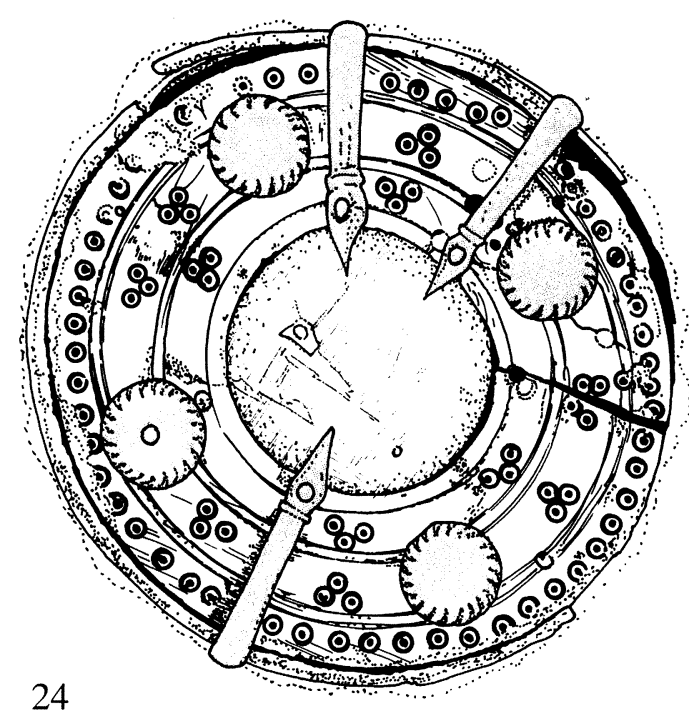

Figura 24. Píxide de San Pedro de la Rúa. Tapa.

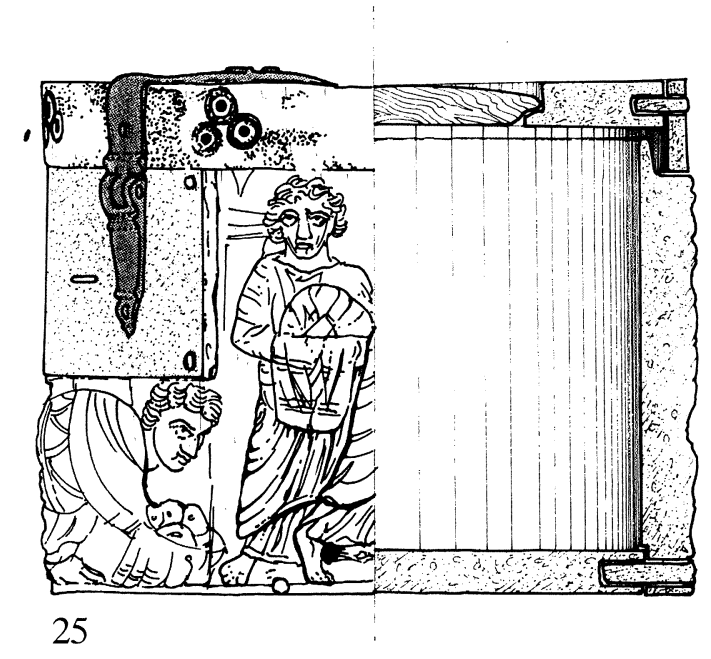

Figura 25. Púxide de San Pedro de la Rúa. Detalle del exterior y sección.

Sólo nos queda por analizar la tapa de la píxide (figs. 22 y 24). Es plana, ajustándose a la sección de la pieza, y está horadada en el centro por un hueco circular de unos cuatro centímetros de diámetro, con lo que resulta un plano de marfil con forma de anillo. Sobre él se disponen tres bisagras con forma de lanza y cuatro cabezas de clavo, circulares, planos, con una somera decoración en los bordes de incisiones oblicuas que forman una especie de sogueado. El campo de marfil se divide en tres bandas concéntricas con una simple decoración geométrica incisa con pequeños círculos con un punto en el centro. La exterior lleva esos circulillos en fila, y las interiores, agrupados en grupos de tres, formando un trébol al ser tangentes las tres circunferencias. Parece que no admite duda la impronta islámica de esta parte de la píxide, que es lo que le da al conjunto una gran originalidad y la identifica como propia de la cultura hispánica por esa mezcla de estilos. Sin duda, la tapa original se rompió en un momento de la Edad Media, algo corriente dada la fragilidad del marfil ${ }^{33}$, y tuvo que ser repuesta por quienes mantenían aún el arte de la eboraria, ya fuesen hispanomusulmanes o mudéjares. Su datación resulta problemática por varias razones, una, por la escasa entidad de la obra en sí, su pequeño tamaño y por constituir una reparación y no una pieza completa ex novo, que diese al artista la posibilidad de expresar su capacidad creadora, y otra, por la pobreza de la decoración, que no permite una certeza en su clasificación estilística. Sin embargo, esa misma sencillez y el planismo de la decoración nos inclina a pensar en la talla almohade. Una arqueta de marfil del Instituto de Valencia de Don Juan ${ }^{34}$ de fines del siglo XII tiene una decoración que deja amplios planos sin labrar y lleva motivos circulares como elementos más destacados, y aparecen también los grupos de tres circulitos con un punto en el centro, igual que la tapa que tratamos. Esta arqueta podría proponerse como modelo al que sigue más tos-

${ }^{33}$ W. F. Volbach, Elfenbeinarbeiten ..., no trata las tapas originales de las píxides, la mayoría de las cuales han desaparecido, si no en su totalidad.

${ }^{34}$ Esta pieza aparece con el núm. 50 del Catálogo de la Exposición Al-Andalus: las artes islámicas en España celebrada en la Alhambra de Granada y en el Metropolitan Museum de Nueva York en 1992, p. 50. 
camente la nuestra. Además, lleva unos remaches en las esquinas que son casi idénticos a las bisagras de la tapa de la píxide de Estella. Resulta algo difícil pensar en el paso de esta obra por talleres musulmanes, parece más lógico pensar que se trata de una obra de un tallista mudéjar que conservase la simplicidad del gusto almohade.

¿Cómo llegó esta píxide a la iglesia parroquia del San Pedro de la Rúa de Estella? Esta pregunta, en otro caso, se hubiese contestado con meras hipótesis: una donación en fecha indeterminada, la lejana posibilidad de que hubiese llegado desde el Sudeste peninsular, y que la pieza arribase desde Oriente durante la dominación bizantina en la segunda mitad del siglo VI y primeras décadas del VII, el fruto de unas posibles relaciones entre la monarquías visigoda y ostrogoda - suponiendo entonces un supuesto origen en Rávena de nuestra píxide-; que llegara con la multitud de reliquias que invadieron el occidente europeo en la época de las Cruzadas, u otras igualmente difíciles de demostrar. Se trata, además, de un objeto casi único en España, exceptuando el díptico consular que se conserva en la Cámara Santa de la Catedral de Oviedo, que se sabe llevado allí desde Roma por el arcipreste de Ribadeo a fines del siglo XIII ${ }^{35}$. Sin embargo, una tradición nos apunta otro origen, no menos sugestivo, que explicaría el origen de la píxide. El relato es recogido por los distintos cronistas de la ciudad navarra, y nos habla de que hacia el año 1270 un obispo de Patrás, en Acaya, resolvió ir en peregrinación a Compostela, y para dejar alli alguna memoria de su visita, decidió llevar como obsequio una espalda del cuerpo de San Andrés apóstol, que había padecido martirio en aquella ciudad y estaba sepultado allí ${ }^{36}$. Sacó testimonio auténtico que, juntamente con la reliquia, incluía una caja para traerla consigo. Llegó a Estella a pie y sin comitiva de criados, habiendo emprendido en esta forma su peregrinación para mayor humildad y mortificación; aquí cayó enfermo y, sin declarar quién era, se hospedó con los demás pobres en el hospital, donde murió en breve, reteniendo siempre pegada a su cuerpo la preciada reliquia que consigo traía. Enterráronle en el claustro de la iglesia de San Pedro, y a la noche siguiente advirtió el sacristán de la iglesia un resplandor como de estrellas sobre la sepultura del obispo peregrino. Repitióse la maravilla en las noches siguientes, y los clérigos, que dudaban de la declaración del sacristán, quedaron desengañados: se registró el sepulcro, y al desnudar el cadáver, hallaron en su pecho la caja de madera y en ella la reliquia de San Andrés y algunas otras, así como la cabeza de un báculo ${ }^{37}$, dos vinajeras y unos guantes de seda de color pardo oscuro ${ }^{38}$. La caja que contenía la reliquia de San Andrés no pudo ser la píxide de marfil, primero por su tamaño, pues la reliquia era un omóplato, y, además, tenemos una descripción: la caja-relicario estaba formada por una hoja de bronce dorado y tenía en sus extremos dos agujeros con cordones, que servían para llevarla colgada al cuello ${ }^{39}$. Este curioso relato, entretejido con lo legendario, no nos explica la presencia de la píxide —que es además demasiado grande para que pueda ocultarse entre las ropas de una persona—,

35 Francisco de Caso; Germán Ramallo, La catedral de Oviedo, León, 1988, pp. 264-265. Este díptico, del cónsul Apión fue realizado en Constantinopla en el 539, según D. Gaborit-Chopin, Op. cit, pp. 29-30.

${ }_{36}$ Eso mismo afirma Santiago de la Vorágine, La Leyenda Dorada, Madrid, 1982, vol. I, pp. 32-35. Sin embargo, la fecha de 1270 de la peregrinación del obispo de Patrás a Compostela no coincide con la situación del sepulçro del apóstol en ese año, pues el cuerpo de San Andrés fue trasladado a Constantinopla bajo el reinado del emperador Constancio II (m. 361) y llevado desde allí a Amalfi después de la toma de la capital bizantina por los cruzados en el 1204.

37 El báculo, del siglo XIII, con esmaltes de Limoges, permaneció en la parroquia hasta 1979.

38 Cit. por Pedro de Madrazo, Op. cit, pp. 83-85 y L. Vázquez de Parga; J. M.. Lacarra; J. Uría, Los peregrinos a Santiago de Compostela, vol. II, p. 138. Siguen ambos el relato incluido en el Extracto de la historia de Estella ... ya citado.

Sebastián Iribarren, Apuntes sobre la historia antigua de Estella, Sevilla, 1912, p. 140. 
pero nos da la pista de que quizás sea el Camino de Santiago la vía por la que pudo llegar, al ser Estella además un hito importante de esa ruta de peregrinación.

Si el camino desde su lugar de producción hasta Estella no está claro, lo está mucho más el que realizó desde Estella a Nueva York. A principios del siglo XX, aprovechando la falta de medios legales para evitarlo y dentro de unas circunstancias bastante propicias a las ventas de bienes muebles eclesiásticos, fue vendida por la parroquia estellesa y pasó a formar parte de la colección de John Pierpoint Morgan y luego a los fondos del Metropolitan $\mathrm{Mu}$ seum de Nueva York, donde hoy se exhíbe ${ }^{40}$.

EMILIo QuintaniLla MarTíneZ Universidad de Navarra

\section{MARI RODRÍGUEZ, «MAESTRA DE VIDRIERAS» EN LA CUENCA DEL SIGLO XVI}

En 1582 el cabildo catedralicio de Cuenca decidió encomendar el cuidado de las vidrieras de su catedral a una mujer, después de haber buscado infructuosamente un maestro durante casi seis años. En efecto, en este año de 1582 la vidriera Mari Rodríguez comenzó a trabajar en la catedral y el canónigo obrero le pagó ocho mil novecientos setenta y ocho maravedíes por «aderezar ... las vidrieras de la yglesia y poner los vidrios y lo demas» ${ }^{1}$.

Mari conocía bien su oficio, había trabajado de forma muy activa con su marido Pedro de Valdivieso ${ }^{2}$ en el taller familiar, como lo reconoció el propio Valdivieso en su testamento cuando dice que en el caso de que su mujer contrajera nuevas nupcias «se le den la mitad de los bienes que yo y ella emos ganado durante el matrimonio» ${ }^{3}$. Cuando Valdivieso murió, Mari se puso al frente del taller y una de las obras que su marido había contratado y que ella se comprometió a realizar, fueron dos vidrieras para la iglesia del monasterio de Monsalud ${ }^{4}$.

40 La píxide ya no estaba en Estella en 1911 (vid. Emilio Quintanilla Martínez, Op. cit., p. 287-288) y en 1914 ya fue exhibida en Nueva York como parte de la Morgan Loan Collection (vid. J. Breck, Op. cit., p. 12.).

1 ADC, Libro de fábrica, 1591-1621, fol. 225.

2 La primera noticia que poseemos sobre Mari Rodríguez data de 1566 y se trata de la siguiente partida de bautismo: «En la ciudad de Cuenca en la perroquia de señor San Miguel oy jueves a veynte y ocho dias del mes de hebrero año de mil y quinientos y sesenta y seis años yo Alonso Portero tiniente de cura de la dicha yglesia batize una niña de Alonso Perez vedriero y de su mujer Angela de Villareal su ligitima mujer que llamaron Maria fue su conpadre de pila Pedro de Valdeyvieso vidriero y aconpañado Juan Lopez calcetero y de capita Mari Rodriguez mujer del dicho Valdeyvieso y aconpañada Rafaela de la Cruz mujer del dicho Juan Lopez». (ADC, Libro de bautismos de San Miguel, 1544-1568). Sabemos que de su matrimonio con Pedro de Valdivieso hubo dos hijas, Mariana y Úrsula.

3 AHPC, Lorenzo Bordallo, 1572 (582), fols. 116v-118.

4 Sepan quantos esta carta de obligación vieren como yo Maria Rodriguez de la Puente viuda mujer que fui de Pedro de Valdibieso vedriero difunto vecino desta noble ciudad de Cuenca como principal deudora e yo Pedro Ruiz barbero vecino desta dicha ciudad como su fiador y principal pagador anbos a dos ... otorgamos e conozemos que por quanto el dicho Pedro de Valdibieso marido de mi la susodicha en su vida se obligo por un conocimiento firmado de su mano de dar hechas e puestas e acabadas dos vedrieras para la iglesia del monasterio de Nuestra Señora de Monsalud las quales dichas dos vedrieras an de ser blancas y las avia de dar fechas 